\title{
Inhaltsverzeichnis
}

Number 1

Editorial: Zur Gründung der Zeitschrift für Naturforschung

P. KARLSON

\section{Original Communications}

Heat Flow Birefringence in Liquids and Liquid Crystals

D. R. BAalss and S. Hess

Shock Wave in Condensed Matter Generated by Impulsive Load

S. I. Anisimov and V. K. Kravchenko

Effective Interactions of Relativistic Composite Particles in Unified Nonlinear Spinor-Field Models. I H. STUMPF

On the Spinodal Decomposition of Wolframite J.-CH. BuHL and A. WiLlgallis

A Study of Portland Cement Hydration by Paramagnetic Iron Suppression of Proton Magnetic Resonance

J. C. Mactavish, L. Miljković, L. J. Schreiner, M. M. Pintar, R. BlinC, and G. LaHaJNAR 32

Irreversible Anaerobic Photoreactions of Phenylazopyrazolone-Dyes in Solution

J. ZeChner, N. Getoff, and St. Stoyanov

$\cdot 37$

Nitrogen Quadrupole Coupling in Ethyl Isocyanide, $\mathrm{C}_{2} \mathrm{H}_{5} \mathrm{NC}$

E. Fliege and H. DreIZler

Direct Determination of the Anisotropy of the Magnetic Susceptibility in Smectic Liquid Crystals G. IllLIAN, H. KNEPPE, and F. SCHNEIDER 46

ESR, Structure and Reactions of Specifically Deuterated $\mathrm{C}_{6}-\mathrm{C}_{8} n$-alkane Cations in Halogenated Matrices

G. Dolivo and A. Lund

On the Matching Spectrum of Rotagraphs

A. Graovac and D. Babić

66
Stacking Faults in $\mathrm{Ca}(\mathrm{OH})_{2}$ Produced by Vapour Phase Hydration

G. SPINOLO and U. ANSELmi Tamburini 73

1 Solute-Solvent Interactions and High Spin $\rightleftharpoons$ Low Spin Transitions in Ferric Dithiocarbamates

P. GANGULI

Solvent Effects on the Kinetics and Mechanism of the Acid-Catalysed Hydrolysis of Ditert.-butylsuccinate in Dioxane-Water Mixtures

Adel N. Asaad and Fayez Y. Khalil

Notes

On the Equivalence of Electromagnetic and ClockTransport Synchronization in Noninertial Frames and Gravitational Fields

H. RUMPF

Elementary Derivation of the Dirac Equation. VIII

H. SALLHOFER

94

Green's Functions in Robertson-Walker-Space

G. SÜSSMANN and H.-D. RADECKE

96

Number 2

\section{Original Communications}

Three-Dimensional Reciprocal Form Factors and Momentum Densities of Electrons from Compton Experiments. I. Symmetry-Adapted Series Expansion of the Electron Momentum Density

E. Heuser-HofmanN and W. Weyrich

Powder Zeeman Study of the Nuclear Quadrupole Resonance Lower Transition Spectrum for $I=5 / 2$; Application to Orthoperiodic Acid

S. Ramaprabhu and K. V. S. Rama RaO 112

A Molecular Dynamics Study of the Structure of an $\mathrm{LiCl} \cdot 4 \mathrm{H}_{2} \mathrm{O}$ Solution P. Bopp, I. OKada, H. Ohtaki, and K. HeinzinGER 
The Chemical Shift of the ${ }^{29} \mathrm{Si}$ Nuclear Magnetic Resonance in a Synthetic Single Crystal of $\mathrm{Mg}_{2} \mathrm{SiO}_{4}$

N. WEIDEN and H. RAGER

Thermodynamics of $\mathrm{Ag}^{0}$-Solvation in Molten Silver Halides, Doped with Metal Halides

T. LIESER and K. G. WeIL

${ }^{19} \mathrm{~F}$ High-Resolution Nuclear Magnetic Resonance Study of Structure and Properties of Crystalline sym- $\mathrm{C}_{6} \mathrm{Cl}_{3} \mathrm{~F}_{3}$

Y. Yoshioka, N. NaKamura, and H. Chihara 137

The Effect of Structural Changes on the Polarizability and Second Hyperpolarizability in Some Benzene Isomers and Their Anions

J. Waite and M. G. PAPADOPOUlos

Pyramidic Mesophases

H. Zimmermann, R. Poupko, Z. Luz, and J. BilLARD

Monte-Carlo Calculations of the Electrical Resistance of Ultra-Thin Metal Films

H.-U. FINZEL and P. WISSMANN

161

An Upper Limit for Birefringence in the Boundary Layer of a Heart Conducting Gas

H. van Houten, W. A. von Marinelli, and J. J. M. BEENAKKER

164

A $94 \mathrm{GHz}$ EPR Spectrometer with Fabry-Perot Resonator

E. Hainde, K. MöBius, and H. OlofF

169

A Phenomenological Theory of Gravitation Based on a Generalization of the Special Relativistic Energy Aspect

F. SPIEWECK

Effective Interactions of Relativisic Composite Particles in Unified Nonlinear Spinor-Field Models. II

H. STUMPF

Notes

Neutron Diffraction with the Metallic Glass $\mathrm{Ni}_{31} \mathrm{Dy}_{69}(+10 \mathrm{a} / \mathrm{O}$ D) Using Isotopic Substitution A. Wildermuth, P. Lamparter, and S. Steeb 191
A Note on Solutions of the Korteweg-de Vries Equation

K. MURAWSKI

Number 3

Original Communications

On the Role of the Nonlocal Hartree-Fock (HF) Exchange in Narrow-Band Materials

M. C. BöHM

Hydrogen Vacancy Diffusion Parameters in $\mathrm{ScH}_{2-x}$ and $\mathrm{ScD}_{2-\mathrm{x}}$ from ${ }^{45} \mathrm{Sc}$ Spin-Lattice Relaxation Time Measurements

M. Jerosch-Herold, L.-T. Lu, D. R. Torgeson, D. T. Peterson, R. G. Barnes, and P. M. RICHARDS

On the Magnetic behaviour of Tetrakis [2-Diethylamino-Ethanolatio- $\mu_{3}-\mathrm{O}$-Copper(II)-Isocyanate] · Trichloromethane, $\mathrm{C}_{28} \mathrm{H}_{56} \mathrm{Cu}_{4} \mathrm{~N}_{8} \mathrm{O}_{8} \cdot \mathrm{CHCl}_{3}$, a Tetrameric Copper(II) Complex with Antiferromagnetic Ground State

L. Schwabe and W. HaASE

Vibrational Spectra and Force Constants of Symmetric Tops VL. Spin Flip Raman Laser Spectra and Rotational Analysis of $\left(v_{1}+v_{2}\right)$ of $\mathrm{CF}_{3} \mathrm{Cl}$ and $\mathrm{CF}_{3} \mathrm{Br}$

M. K. Haj-Abdallah, H. Pascher, H. G. Häfele, A. Ruoff and H. Essig

233

Fast Reactions Involving Radical-Cations During their Geminate Recombination as Studied by the OD ESR Method

V. O. Saik, O. A. Anisimov, V. V. Lozovoy and YU. N. Molin

An Application to $\mathrm{H}_{2}^{+}$of Laplace Type Integral Transform and its Inverse

M. Primorac and K. KovaČEvić

The ESR-absorption of Antiferromagnetic Compounds and its Deviation from the Lorentzian Profile (In German)

K. DRÄGER

On the Habit of Blue Phase II Liquid Single Crystals

TH. BLÜMEL and H. STEGEMEYER

260 
Determination of a High Barrier Hindering Internal Rotation from the Ground State Spectrum. The Methylbarrier of 1-Butyne

G. BestmanN and H. DREIZleR

263

A Redetermination of the Barrier to Internal Rotation of 2-Fluoropropene

G. Bestmann and H. Dreizler

Determination of a High Barrier Hindering Internal Rotation from the Ground State Spectrum. The Methylbarrier of Propane

G. Bestmann, W. Lalowski and H. Dreizler 271

Anomalous Temperature Dependence of the ${ }^{127} \mathrm{I}$ Quadrupole Coupling in $\left(\mathrm{C}_{6} \mathrm{H}_{5}\right)_{4} \mathrm{PIO}_{4}$, $\left(\mathrm{C}_{6} \mathrm{H}_{5}\right)_{4} \mathrm{AsIO}_{4}$ and $\left(\mathrm{C}_{6} \mathrm{H}_{5}\right)_{4} \mathrm{SbIO}_{4}$

P. K. Burkert and D. G. KlobasA

Photochemival $(2+2)$ Cycloadditions to the $\mathrm{C}=\mathrm{N}$ Double Bond - a Theoretical Study on the Regioselectivity (In German)

W. FABIAN

The Nuclear Magnetic Shielding of the ${ }^{19} \mathrm{~F}-$ Nuclei in $\mathrm{KZnF}_{3}$

R. GROSESCU and U. HAEBERLEN 283

Effective Interactions of Relativistic Composite Particles in Unified Nonlinear Spinor-Field Models. III

H. STUMPF

\section{Number 4}

\section{Original Communications}

The Reflectivity of $\mathrm{Rb}$ and Cs Suboxides

(In German)

G. Metsch, W. Bauhofer, and A. Simon

303

Influence of Quenching upon the Rotational Depolarization of Fluorescence

A. KawsKi, Z. KoJro, and A. KUbICKI

Determination of Partial Photochemical Quantum Yields of Reversible Photoisomerizations of Stilbene-1 Derivatives

G. Gauglitz, R. Goes, W. Stooss, and R. RAUE
The $\mathrm{C}-\mathrm{Cl}$ Bonds in $\alpha$-2,4,6-tris(trichloromethyl)1,3,5-trioxane, $\alpha$-Parachloral, $\left(\mathrm{Cl}_{3} \mathrm{CCHO}\right)_{3}$. A ${ }^{35} \mathrm{Cl}-\mathrm{NQR}$ Single Crystal Study

M. Hashimoto, N. Weiden, and A. Weiss

On the Chemical Bonding in the Intermetallic B32Type Compounds LiMe $(\mathrm{Me}=\mathrm{Al}, \mathrm{Zn}, \mathrm{Ga}, \mathrm{Cd}$, and In)

P. C. SCHMIDT

${ }^{1} \mathrm{H}$ NMR and Differential Scanning Calorimetry Studies of Molecular Motion and Phase Transition in Butylammonium Iodide

S. FuKada, R. IKEDA, and D. NAKamura

Deuterium NQR Spectra: Dipolar Interaction Between Two Quadrupolar Nuclei

N. HADIPOUR and J. L. RAGLE

Nitrogen-14 Quadrupole Coupling Constants in Propanedinitrile, $\mathrm{CH}_{2}(\mathrm{CN})_{2}$, by Microwave Spectroscopy

A. P. Cox, Y. Kawashima, E. Fliege, and H. DREIZLER

Kinetics of the $\mathrm{Ce}^{3+} / \mathrm{BrO}_{2}$-Reaction in Sulfuric Acid Medium

H. D. Försterling, H. J. LAMberz, and H. SCHREIBER

Molecular Vibrations of Aluminum Trichloride Monomer with Application of the Keating Bendings

T. Mogstad, S. J. Cyvin, B. N. Cyvin,

J. Brunvoll, and G. Díaz Fleming

Exact Green's Function for the Finite Rectangular Potential Well in One Dimension

R. BALTIN

Vibrational Spectra and Force Constants of Symmetric Tops, XLVII. Rovibrational Spectra of Three Monoisotopic $\mathrm{H}_{3} \mathrm{GeCl}$ Species in the $v_{6}$ Region

H. Bürger, P. SCHUlz, and S. Cradock

The Ground State Rotational Constants of $\mathrm{H}_{3} \mathrm{SiD}$

H. BÜrger, A. RahNeR, and J. KaUpPINEN 386

An Electron Spectroscopical Interpretation of the Conformation of Dimeric Porphine Derivatives by the Extended Dipole Model (In German)

B. von MaLTZAN

389 
Effect of Finite Ion Temperature and Modulational Instability of Ion-Acoustic Waves in Presence of an Inhomogeneous Plasma

S. BHATTACHARYYA and R. K. Roy CHOUdHURY

Concentration Fluctuations in Liquid Alloys of Alkali Metals from Semiempirical Theories of Mixtures

L. J. Gallego, J. A. Alonso, and J. A. SomozA

Notes

Thermospray Mass Spectrometry, a New Technique for Studying the Relative Stability of Cluster Ions of Salts

G. SChMELzeisen-Redeker, S. S. Wong,

U. Giessmann, and F. W. Röllgen

430

\section{Number 5}

\section{Original Communications}

Electronic Structure of a Single Hydrogen Centre in Magnesium Crystals

R. Duscher and J. K. Maichle

Lattice Statics of a Hydrogen Centre in Magnesium

B. Bratschek, B. Rager, and H.-J. Volkert 439

Asymptotic Freedom and QCD Scaling Law

J. SidHANTA and R. RoychoudHURY

Group Theoretic Approach to the Exponential Cosine Screened Coulomb Potential

B. Roy (née GHOSh) and R. Roy Choudhury 453

Time Quantization and Quantum Mechanics (In German)

M. BÖRNER

456

The Energy Dependence of the Imaginary Nuclear Potential

E. F. HeFter

462

Smectic C to Nematic Phase Transition Studies in NOBA

N. V. S. RaO and V. G. K. M. Pisipati

466
ESR Study of Molecular Ordering in 50.1, 50.2 and 50.4

N. V. S. Rao, V. G. K. M. Pisipati, P. V. Datta Prasad, and D. SARAN

Density, Refractive Index and Ultrasonic Velocity Studies Involving N-(p-n-Pentyloxybenzylidene)p-n-octylaniline

V. G. K. M. Pisipati, N. V. S. Rao, P. V. Datta Prasad, and P. R. Alapati

Analysis of "Hot" Bands Associating to the $v_{2}$ Fundamental Band of $\mathrm{HC}_{5} \mathrm{~N}^{1}$

K. M. T. Yamada and G. WinNEWisSER

Surface Analysis and Structures Spherical Crystals of Very Clean $\mathrm{Au}, \mathrm{Cu}$ and $\mathrm{Au}-\mathrm{Cu}$ Alloys Grown from a Drop of Melt

B. Grosser and E. Menzel

Numerical Investigation of Laser Oscillation in a Recombining Hydrogen Plasma Interacting with Helium Gas in TPD-I

T. ODA and U. FuruKane

485

The Structure of Some Univalent Metal Nitrate Melts Studied by Means of Pulsed Neutron Diffraction

T. Yamaguchi, Y. Tamura, I. OKada,

H. OHTAKi, M. Misawa, and N. Watanabe

490

On the Photoluminescence of Thiophene Benzologues (In German)

M. ZANDER

Cathodoluminescence of the Rare Earth Activated Host Lattices $\mathrm{Sr}_{3} \mathrm{La}_{2} \mathrm{~W}_{2} \mathrm{O}_{12}$ and $\mathrm{Ca}_{2} \mathrm{La}_{0.5} \mathrm{Na}_{0.5^{-}}$ $\mathrm{WO}_{6}$ (In German)

R. BRAUN, R. OtTO, W. WischerT, and S. KEMMLER-SACK

The Rotational Spectrum of Propane Centrifugal Distortion Analysis

G. Bestmann, H. Dreizler, J. M. Vacherand, D. BOUCHER, B. P. van EIJCK, and J. Demaison

Electron Paramagnetic Resonance and Optical Absorption Spectra of $\mathrm{VO}^{2+}$ in $\mathrm{CsCl}$ Single Crystals

G. ElBers and G. LeHMANN 511 
The Stability of Rare Gas Clusters by Ionization

E. E. Polymeropoulos, S. Löffler,

and J. BRICKMANN

Molar Volume of Molten Binary $\mathrm{CaCl}_{2}-\mathrm{NaCl}$, $\mathrm{LaCl}_{3}-\mathrm{NaCl}$, and $\mathrm{LaCl}_{3}-\mathrm{CaCl}_{2}$ and Ternary $\mathrm{LaCl}_{3}-\mathrm{CaCl}_{2}-\mathrm{NaCl}$ Systems

K. Igarashi, Y. IWADATE, H. OHNo, and J. MOCHINAGA

Singlet Mechanism for Trans $\rightarrow$ Cis Photoisomerization of Quaternary Salts of 4-Substituted 4'-Azastilbenes $\left(\mathrm{R}=\mathrm{CN}, \mathrm{H}, \mathrm{CH}_{3}\right.$, and $\left.\mathrm{OCH}_{3}\right)$ and their Quinolinium Analogues. VIII

H. GÖRNER, A. FoJTIK, J. WróbleWSKI, and L. J. CURRELL

\section{Notes}

Transitivity of "Gravitational Transformations"

$$
\text { F. SPIEWECK }
$$

${ }^{57} \mathrm{Fe}$ Isomer Shift Calibration Experiment

H. Daniel, F. J. Hartmann, and B. Pitesa

Number 6

\section{Original Communications}

Thiophosphonyl Radicals. Photolytic Generation and Reactivity Towards Olefinic Compounds

T. Sumiyoshi, W. Weber, and W. Schnabel 541

Glass Forming Ability of GeTeSn with Tin Concentration and Initial Conditions

B. Arcondo, G. Quintana, and H. Sirkin 544

Mössbauer and X-Ray Studies on Splat Cooled $\mathrm{SnGeCu}$ Alloy

H. Sirkin, B. Arcondo, E. Duhalde,

E. NASSIF, and G. QUINTANA

548

Evaluation of Partial Structure Factors in the Small $Q$-Region with Amorphous $\mathrm{Ni}_{80} \mathrm{P}_{20}$ by Neutron Diffraction Using Isotopic Substitution

K. SCHILD, F. Frisius, P. LAMPARTER, and S. STEEB

Temperature Dependence of Limiting Fluorescence Anisotropy of POPOP in Cellulose Acetate Film A. KaWSKI, A. KUbicki, I. WeYna, and I. Janić
Hyperchaos in the Post-Breakdown Regime of pGermanium

J. Peinke, B. Röhricht, A. Mühlbach,

J. PARisi, Ch. Nöldeke, R. P. Huebener, and O. E. RöSSLER

Pyroelectricity of Molecular Crystals: Benzene Derivatives
T. ASAJI and A. WeISS
567

Determination of a High Potential Barrier Hindering Internal Rotation from the Ground State Spectrum. The Methylbarrier of Ethylbromide

J. GripP, H. Dreizler, and R. SCHWARZ 575

Dielectric Relaxation in Binary and Ternary Mixtures of Ethanol, Water, and Benzene or n-Hexane

H. Utzel and M. Stockhausen 588

$\mathrm{CH}_{3}$ Rotational Tunnelling in Alkali Acetates and Correlation between NMR Spin-Lattice Relaxation and Neutron Scattering Data

A.-S. MontJoIE and W. MülleR-Warmuth 596

Interrelation between Molecular Motions and Phase Transitions in Monomethylammonium Perchlorate. A Study by DSC, Proton, and Deuteron NMR S. JURGA and H. W. SPIESS

602

A Reactive System with Diffusive Transport Displaying Two Different Symmetry-Breaking Dissipative Structures

A. Fernández and O. SinanoĞlu

611

Conformational Investigations of Tetrahydroisoquinoline and Tetrahydronaphthalene-Semiquinones by ESR-Spectroscopy (In German)

K. SChefFler, K. Stolze, and $\mathrm{H}$. B. STEgmanN

619

Megahertz Dielectric Relaxation in the Nematic Phases of 4,4'-di-n-propyloxyazoxybenzene and 4,4'-di-n-pentyloxyazoxybenzene

N. X. Phuc, W. Otowski, J. Chruściel, H. KresSe, S. Urban, and S. Wróbel

Effect of Pressure on Strongly Polar Liquid Crystals S. K. Prasad, S. Pfeiffer, G. Heppke, and R. SHASHIDHAR 
On Topology-Property Relations of Polycyclic Aromatic Hydrocarbons M. ZANDER

Coriolis Coupling Constants and Inertia Defect of Urea

M. Campos-Vallette, C. A. Acevedo-Gonzalez, G. Diaz F., and R. PEÑa C.

An Intermolecular Potential Function for CyclenWater Derived from Ab-Initio Molecular Orbital Calculations

Supot V. Hannongbua and B. M. Rode

644

\section{Notes}

A Note on the Stratified Turbulent Flow with no Shear

A. K. Chakraborty and H. P. Mazumdar 649

Elementary Derivation of the Dirac Equation. IX

H. SALLHOFER

Number 7

\section{Original Communications}

Rate Dependent Constitutive Equations of Cyclic Softeni,g

J. S. Mshana and A. S. Krausz

Generalized Hamiltonians, Functional Integration and Statistics of Continuous Fluids and Plasmas

H. TASSO

Laser-Desorbed Large Molecules in a Supersonic Jet H. v. Weyssenhoff, H. L. Selzle, and E. W. SCHLAG

Properties of Cold Condensed Silver Chloride and of Cocondensed Silver/Silver Chloride Films. - I. UV-VIS-Spectra

H. Gottwald, T. Lieser, K. G. Weil, and A. WEISS

J-Dependence of $\mathrm{T}_{2}$-Parameters for Rotational Transitions of $\mathrm{SO}_{2}$ and $\mathrm{CH}_{3} \mathrm{OH}$ in $K$-Band

S. C. Mehrotra, H. Dreizler, and H. Mäder 683

Phototransformation of Air Pollutants: Rapid Test for the Determination of $k_{\mathrm{OH}}$

W. Klöpffer, G. Kaufmann, and R. Frank 686
The Pressure Dependence of the Phase Diagram t-Butanol/Water

M. WOZNYJ and H.-D. LÜDEMANN

Photoluminescence and Sensitized IR Emission of the Trivalent Rare Earths in $\mathrm{Ca}_{3} \mathrm{La}_{2} \mathrm{Te}_{2} \mathrm{O}_{12}$ (In German)

H.-D. Autenrieth, B. Kottmann, and S. KemmLER-SACK

Photoelectron Spectra and Electronic Structure of Some Steroids

N. BHACCA and L. KLASINC

706

Synthesis, Vibrational Spectra and Normal Coordinate Analysis of Cesium-Hexathiohypodiphosphate $\mathrm{Cs}_{4} \mathrm{P}_{2} \mathrm{~S}_{6}$

S. J. Cyvin, B. N. Cyvin, C. Wibbelmann, R. BeCKer, W. BrockNer, and M. PARENSEN 709

Molecular Vibrations of Gallium Trichloride Monomer with Application of the Keating Bending

B. N. Cyvin, S. J. Cyvin, G. Diaz Fleming, T. MOgStad, and E. RytTer

On the Interpretation of the Influence of Substituents on the UV Spectra of

W. FABIAN

Crystal Structure of [N, N'-di(n-propyl)-4,4'-bipyridinium $]^{2+}(7,7,8,8 \text {-Tetracyano-p-quinodimethanide })_{4}^{2-}$ G. J. AshWELL and S. C. WALLWORK

Evidence of Back Charge Transfer in DMBP-TCNQ G. J. Ashwell, G. H. Cross, I. M. Sandy, W. WACLAWEK, and M. ZABKOWSKA 731

Qualitative Properties of Autocatalytic Reactions Occurring in a Flow System

S. H. Kim and V. HLA VACEK

Interferences with an Plane Parallel Plate Near the Critical Angle of Total Reflection

K. Eidner, G. MAyer, and R. Schuster

748

Formfactors of Relativistic Composite Particle Interactions in Unified Nonlinear Spinorfield Models H. STUMPF

752 
Number 8

\section{Original Communications}

On the Theory of a Non-Periodic Quasilattice Associated with the Icosahedral Group

P. KRAMER

775

Numerical Integration of the Navier-Stokes Equations for a Disk Rotating in a Housing

A. F. Borghesani and L. BRUSCHI 789

Pressure Effects of Foreign Gases on the $535.0 \mathrm{~nm}$ Fluorescence Line of Thallium

E. LISICKI, A. BIELSKI, J. SZUDY, and J. WoLNIKOWSKI 800

An Investigation of Non-Equilibrium Effects in Thermal Argon Plasmas

C. J. Timmermans, R. J. Rosado, and D. C. SCHRAM

810

Finite-Resistivity Effects on Rayleigh-Taylor Instability of a Stratified Plasma Including Suspended Particles

R. Sanghvi and R. K. ChHaJlani

826

Phonon Density of States and Debye Temperatures of BCC Transition Metals

A. R. JANI

Calcium Isotope Effects in Ion Exchange Electromigration and Calcium Isotope Analysis by Thermo-Ionization Mass Spectrometry

Y. Fuji, J. Hoshi, H. Iwamoto,

M. OKAMOTO, and H. KaKiHANA

The $\mathrm{S}_{1} \rightarrow \mathrm{S}_{n}$ and $\mathrm{T}_{1} \rightarrow \mathrm{T}_{n}$ Absorption Spectra of Some Anthracene Derivatives

J. SZCZEPAŃSKI and J. HELDT

CNDO/S-CI Calculations of Some Carbonyl-containing Organic Luminophores with a Stilbene Subchromophore

G. Olbrich, P. Nikolov, F. Fratev $(\dagger)$, and O. E. PolansKy

Notes

The Molecular Electric Dipole Moment for 1,2,4Trifluorobenzene and a Comparison with Related Molecules

J. SPIECKermann and D. H. Sutter

864
Number 9

Original Communications

Chaos-Induced Diffusion. Analogues to Nonlinear Fokker-Planck Equations

H. Fujisaka, S. Grossmann, and S. Thomae 867

Electric Field Dependence of the Fluorescence Intensity of Solute Molecules and Fourth Order Effects

H. BISCHOF and W. BAUMANN

874

Entropy Production in Oscillating Chemical Systems

B. Å. G. MÅNSSON

877

New Approach, Taking into Account Elastic and Inelastic Processes, for Transport Properties of a two Temperature Plasma

C. Bonnefoi, J. Aubreton, and J.-M. Mexmain

Raman, Visible and Ultra-violet Spectral Studies of Ionic Interactions in Molten Alkali Nitrate and Nitrite Systems

K. SAKaI and T. NAKAmURA

ESR of ${ }^{\cdot} \mathrm{NH}_{2}$ and ${ }^{\cdot} \mathrm{N}_{2} \mathrm{H}_{4}^{+}$Free Radicals Produced by Gamma Irradiation in $\mathrm{NH}_{3} \mathrm{OHCl},\left(\mathrm{NH}_{3} \mathrm{OH}\right)_{2}$ $\mathrm{SO}_{4}$ and $\mathrm{N}_{2} \mathrm{H}_{6} \mathrm{SO}_{4}$

F. KöKSAL, O. ÇAKIR, İ. GÜMRÜKÇÜ, and M. BIREY

903

Internal Cation Mobilities in the Ternary Molten System ( $\mathrm{Li}, \mathrm{Na}, \mathrm{K}) \mathrm{NO}_{3}$ of the Eutectic Composition
J. HABASAKI and I. OKADA
906

Vibrational Spectrum and Normal Coordinate Analysis of AlPS 4 tetrahedral Chains (In German) C. Wibbelmann, B. N. Cyvin, and S. J. Cyvin 909

The Microwave Spectrum of 3,4-Dihydro-1,2-Pyran

J. C. LóPEZ and J. L. Alonso

913

Boron Hyperfine Structure in TrifluorophosphineBorane

W. Kasten, H. Dreizler, and R. L. KuczKowski 920 
Topological Properties of Benzenoid Systems. Characterization of Certain Chemical Graphs

I. GUTMan and S. El-BasiL

Valence Force Constants of Carbonyl Bonds in Naphthaldehydic Compounds as Chemical Binding Correlation Parameters

V. Vargas, E. Clavijo, and R. G. E. Morales 927

Determination and Analysis of the Physical Properties of a New Class of Polar Nematic Liquid Crystals

HP. SCHAD and S. M. Kelly

Bulk Polaritons in $\mathrm{K}_{2} \mathrm{Mg}_{2}\left(\mathrm{SO}_{4}\right)_{3}$ Observed by the ATR-Method

M. BEHMER

Enthalpies of Mixing for Binary Liquid Mixtures of Monocarbonic Acids and Alcohols

R. HAASE and R. LORENZ

Burgers Equation for Wave Propagation in an Infinite Stout-Wall Tube

K. MURA WSKI

952

The Korteweg de Vries Equation for Wave Propagation in an Infinitely Long Thin Walled Circular Cylinder Obtained via the Lagrangian Method

K. MURA WSKI 955

Notes

On Chiral Symmetry Breaking in a Non-Simply Connected Space-Time

P. RoY and R. ROYCHOUDHURY

\section{Number 10}

\section{Original Communications}

Hamiltonian Approach to Magnetic Fields with Toroidal Surfaces

A. SAlat

959

Surface Excitations of a Compressible Cylindrical Liquid
A. Müller and S. GrossmanN

968
Scalar Fluctuations from Extended Non-equilibrium Thermodynamic States

R. E. NetTLETON 976

The Specific Heat of $\mathrm{Ag}_{2} \mathrm{~S}$ in $\alpha$-phase

H. OKAZAKI and A. TAKano

Vibrational Spectra and Force Constants of Symmetric Tops, IL. The $v_{3}$ Fundamental of Unstable $\mathrm{H}_{3} \mathrm{SnCl}, \mathrm{H}_{3} \mathrm{SnBr}$, and $\mathrm{H}_{3} \mathrm{SnI}$ Studied by High Resolution FT Spectroscopy of Monoisotopic Species

H. BÜRGER and M. BETZEL

Direct Calculation of Natural Orbitals of Two-Electron Systems

H. KLEINDIENST and K. RosSeN 995

Molecular $g$-values, Magnetic Susceptibility Anisotropies, Molecular Electric Quadrupole Moments, improved Molecular Electric Dipole Moments and ${ }^{14} \mathrm{~N}-\mathrm{Quadrupole}$ Coupling Constants of Acrylonitrile, $\mathrm{H}_{2} \mathrm{C}=\mathrm{CH}-\mathrm{CN}$, and the Magnetic Susceptibility Tensor of the Nitrile Group

M. STOLzE and D. H. SutTer

998

Analytical Properties of Poincaré Halfmaps in a Class of Piecewise-Linear Dynamical Systems

C. KAHLERT and O. E. RöSSLER

1011

Radiation Chemical Studies of the Oxidation of Aniline in Aqueous Solution

LING QIN, G. N. R. Tripathi, and R. H. SCHULER

1026

Photoreactions of 2,6-Diphenyl-s-Hydrindacene1,3,5,7-Tetrone and its Derivatives in Polar and Nonpolar Solvents

I. TimtcheVa, J. Zechner, N. Getoff, and ST. MINCHEV

1040

Phosphorescence of Cyclophanes and Cyclophane/ $\mathrm{Ag}^{+}$Complexes

H. Hopf and M. ZANDER

1045

Localization of Discrete Spectrum of Multiparticle Schrödinger Operators

HEINZ K. H. SiEDENTOP

1052 
Monte Carlo Approach to Total $\pi$-Electron Energy of Conjugated Hydrocarbons

I. GUTMAN and M. RAŠKOVIĆ

1059

Gel'fand-Yaglom Wave Equations based on the Representation $(3 / 2,5 / 2) \oplus(1 / 2,5 / 2) \oplus(-1 / 2$, $5 / 2) \oplus(-3 / 2,5 / 2)$. Charge and Causality

C. G. Koutroulos

1062

Notes

The Temperature Coefficient of the Resistance of Ultra-Thin Metal Films from Computer Simulations H.-U. FINZEL and P. WissmanN

1066

Number 11

\section{Original Communications}

Vector Potential and Magnetic Field of Current-carrying Finite Elliptic Arc Segment in Analytical Form

L. URANKAR

1069

Tunneling Spectroscopy by Nuclear Magnetic Resonance: Analysis of Rotational Tunneling in Solid Pentamethylbenzene

W. T. Sobol, K. R. SRIDHaran,

I. G. CAMERon, and M. M. Pintar

1075

Isotope Effects on Deuterium Spin-Lattice Relaxation in $\mathrm{H}_{2} \mathrm{O} / \mathrm{D}_{2} \mathrm{O}$ Mixtures

M. KaKihana, M. ОKamoto, and T. NAGUMO

1085

Polarization Inhomogeneity Effects in Microwave Fourier Transform Spectroscopy

W. STAHL and H. DreizLER

1096

Temperature Dependence of Regioselectivity and Excimer Equilibrium in the Photodimerization of 9-Methylanthracene

T. WolfF

1105

Molecular Shape Descriptors. 1. Three-Dimensional Molecular Shape Descriptor

I. Motoc, G. R. MARShall,

R. A. DAMmKoEHLER, and J. LABANOWSKI

1108
Molecular Shape Descriptors. 2. Quantitative Structure-Activity Relationships Based Upon ThreeDimensional Molecular Shape Descriptor I. Motoc and G. R. MARSHALL

Molecular Shape Descriptors. 3. Steric Mapping of Biological Receptor

I. Motoc, G. R. MARSHALl, and J. LABANOWSKI

Kinetics and Mechanism of the Change of the 4-Nitrobenzylthio-System into 4,4'-Diformylazoxybenzene in Alkaline Dioxane-Water Media Y. Riad, A. N. AsAad, G.-A. S. Gohar, and A. A. AbDallah

1128

Coupling Schemes for Cubic Complexes

J. R. Perumareddi

The Polarizability and Second Hyperpolarizability of the Phenyl Cation

M. G. PAPAdopoulos and J. Waite

1140

Quantumchemical Calculations on Nitrogen Bases. Part 3: Ab initio- and Semiempirical Calculations on the Protonaffinity of some Secondary, Tertiary and Branched Primary Aliphatic Amines (In German)

E. Heyne, H. Niephaus, G. RaAbe,

W. SCHLEKER, and J. FleischHAUER

1143

Viscosity, Conductivity and Density of Fused Silver Chloride Doped with $\mathrm{MeCl}_{n}(\mathrm{Me}=\mathrm{Li}, \mathrm{K}, \mathrm{Cs}, \mathrm{Ba})$ in the Mole Fraction Region $0 \leqq x_{\text {dopant }} \leqq 0.1$

G. G. W. Greening and K. G. WeIL

1151

The Solution-State Conformations of 2,4,6-Tri- $t$ butyl-benzaldehyde and -thiobenzaldehyde H. Lumbroso, J. CurÉ, R. OKazaki,

A. ISHII, and N. INAMOTO

1157

Notes

Diffraction Pattern and Layer Structure of a Quasilattice

P. KRAMER and L. Kramer

1162

Optical Absorption Spectra of Vanadyl Ion (Impurities) in Three Host Crystal Compounds

O. P. Agarwal and P. Chand

1164 
Upper Bound for Total $\pi$-Electron Energy of Benzenoid Hydrocarbons

J. Cioslowski

The Use of the Gauss-Chebyshev Quadrature in Estimation of the Total $\pi$-Electron Energy of Benzenoid Hydrocarbons

J. CiosŁowsKI

\section{Number 12}

\section{Original Communications}

The World is Steadily Coming to Be (In German)

$$
\text { F. BOPP }
$$

On Energy and Angular Distributions of Electrons in Triplet Production

E. HAUG

Einstein Condensation in a Macroscopic Field

R. BRENDLE

Semiempirical Theory of Solid Solubility in Transition Metal Alloys

J. M. LóPEZ and J. A. Alonso

Intramolecular Dipole Reorientation and Dielectric Loss of Microwaves and Submillimetrewaves in Diluted Solution. III. Methylethers (In German)

G. KLAGES

1206

Microwave Absorption in a Plasma Resonator operated with Hydrogen

G. Himmel and M. OSTERHOLD

Mono- and Bistable Mixtures of Interacting Antipodes

A. KLEMM

Refractive Index of Molten $\mathrm{LiNO}_{3}-\mathrm{KNO}_{2}$ and $\mathrm{NaNO}_{3}-\mathrm{NaNO}_{2}$ Systems

Y. Iwadate, J. TOMinaga, K. Igarashi, and J. MOchINAGA

1232

Molecular Dynamics Study of the Effect of Pressure on an Aqueous $\mathrm{NaCl}$ Solution

G. Jancsó, K. Heinzinger, and P. BopP

1235
Crystal Structure and Vibrational Spectrum of $\mathrm{Tl}_{4} \mathrm{P}_{2} \mathrm{Se}_{6}$ (In German)

W. Brockner, L. OHSE, U. PätzmanN, B. EISENMANN, and H. SCHÄFER

Number of Kekulé Structures of Five-Tier Strips

S. J. Cyvin, B. N. Cyvin, and I. Gutman

Boron and Nitrogen Hyperfine Structure in the Microwave Spectrum of Trimethylamine-Borane W. Kasten, H. Dreizler, and R. L. KUCZKOWSKI

$\mathrm{X} \alpha$ SW Calculations for Trimethylaluminium and Trimethylborane (In German)

H. SCHILDER and W. SCHLEKER

Solvation of Coordinatively Saturated Metal Complexes of Nitrogen Ligands

A. N. Kitaigorodski and A. N. BelyaeV

1271

MINDO-Forces Study on the Relative Stabilities of Hydroxy- and Aminopyridine Tautomers

S. M. KHALIL

1278

Effects of Periodic and Stochastic Perturbations on Oscillations and Chaos in a Model of the Peroxidase-Oxidase Reaction

L. F. OLSEN

1283

The Reaction $\mathrm{CH}_{2} \mathrm{OH}$ Radicals with $\mathrm{O}_{2}$ Studied by Laser Magnetic Resonance Technique

S. Dóbé, F. Temps, T. Böhland, and H. GG. WAGNER

1289

On the Validity of the Mulliken-Type Model in Describing the Benzene-Tetracyanoethylene Complex

J. CiosŁowski and A. M. TureK

1299

CNDO/S-CI-Calculations on the Circular Dichroism of Disulfide Linkages in Proteins in the Near UV (In German)

H. NiEPhaus, W. SCHLEKer, and J. FleisChHAUER

1304

Smectic $A_{l}-$ Smectic $A_{d}$ Transition in Binary Mixtures of Compounds with Strongly Polar Terminal Groups

Ch. Bahr, G. Heppke, and R. Shashidhar 1311 
Phosphorescence Properties of $[2,2](1,4)$ Naphthalenoparacyclophane and [2,2] $(1,4)$ Chrysenoparacyclophane and their Ground State Complexes with Silver Perchlorate (In German)

H. Hopf, M. ZANDER, and J. HuCKer

1316

Coordination of Rhodium(III) in Dilute Aqueous Solutions in Presence of Chloride Anion

R. Caminiti, C. Atzei, P. Cucca, F. Squintu, and G. BONGIOVANNI

1319

A Spectroscopic Study of Pivalophenone, 2-Pivaloylfuran, 2-Pivaloylthiophen and 2-Pivaloylselenophen, and their Sulphur Analogues

C. G. ANDrieu and H. Lumbroso

1329

Preferred Conformations of Pivalophenone, (2-Pivaloyl)- and (2-Aroyl)-furans, (2-Pivaloyl)- and (2Aroyl)-thiophens, (2-Pivaloyl)- and (2-Benzoyl)selenophen, and their Sulphur Analogues
H. Lumbroso, C. Liégeois, and C. G. ANDRIEU

1338

Notes

A High-Resolution Time-of-Flight Mass Spectrometer Using Laser Resonance Ionization R. Frey, G. Weiss, H. Kaminski, and E. W. SCHLAG

1349

Has Liquid Formamide a Linear-Chain Structure or Ring-Dimer Structure?

H. OHTAKI and S. ITOH

Sachverzeichnis

Authors Index

1359 
